\title{
Uma deposição funerária Guarani no alto rio Uruguai, Santa Catarina: escavação e obtenção de dados dos perfis funerário e biológico
}

\section{A Guarani burial deposit on the upper Uruguay River, Santa Catarina: excavation and collection of data on the biological and funerary profiles}

\author{
Mirian Carbonera', Sérgio Francisco Serafim Monteiro da Silva", Antoine Lourdeau III, Iv, \\ Ana Lucia Herbertsv , Francieli Kuczkovskil, Christine Hattévi , Michel Fontugnev ${ }^{v}$, André Luiz Ongherol, \\ Jéssica Pedroso Brizola! Marcos César Pereira Santos ${ }^{\text {VII }}$ \\ Universidade Comunitária da Região de Chapecó. Centro de Memória do Oeste de Santa Catarina. Chapecó, Santa Catarina, Brasil \\ "Universidade Federal de Pernambuco. Recife, Pernambuco, Brasil \\ IIIMuséum National d'Histoire Naturelle. Paris, França \\ vUniversidade Federal de Sergipe. São Cristóvão, Sergipe, Brasil \\ v'Scientia Consultoria Científica. Florianópolis, Santa Catarina, Brasil \\ "Laboratoire des Sciences du Climat et de l'Environnement. Gif-sur-Yvette, França \\ VIILaboratório de Arqueologia Pedro Ignácio Schmitz. Criciúma, Santa Catarina, Brasil
}

\begin{abstract}
Resumo: Este trabalho apresenta os resultados da escavação de uma deposição funerária relacionada à unidade arqueológica Guarani, encontrada no setor 2 do sítio multicomponencial ACH-LP-07, na margem direita do rio Uruguai, município de Águas de Chapecó, Santa Catarina. São apresentados os procedimentos empregados em campo e em laboratório para escavação e análise tipológica de um recipiente cerâmico utilizado como urna funerária, bem como é feita análise das características dessa deposição e dos remanescentes ósseos humanos e a sua inclusão no contexto regional do alto rio Uruguai. Uma data de ${ }^{14} \mathrm{C}$ de fragmento de carvão recuperado no entorno da deposição funerária revelou idade de $395 \pm 40$ AP, já adentrando o período colonial, mas sem evidências materiais de contato com os europeus. A análise da estrutura do enterramento contribui com novas informações relacionadas ao comportamento funerário da unidade Guarani, visto que, apesar de ser muito descrita pela literatura, carece de contextos documentados na perspectiva arqueológica.
\end{abstract}

Palavras-chave: Alto rio Uruguai. Deposição funerária. Unidade arqueológica Guarani.

Abstract: This work presents the results from excavating a funerary arrangement related to the Guarani archaeological unit found in sector 2 of the ACH-LP-07 multicomponent site on the right bank of the Uruguay River in Águas de Chapecó, Santa Catarina. The procedures used in the field and laboratory to excavate and conduct typological analysis of a ceramic vessel used as a funeral urn and to describe this arrangement, the human skeletal remains, and their inclusion within the regional context of the upper Uruguay River are presented for future archaeological interpretation. Carbon 14 dating of a charcoal fragment recovered from the area surrounding the funerary site revealed an age of $395 \pm 40 \mathrm{BP}$, at the beginning of the colonial period, but no material evidence of contact with Europeans was found. Analysis of the burial structure contributes new information on the funerary behavior of the Guarani unit, because even though it has been thoroughly described in the literature, contexts documented from an archaeological perspective are lacking.

Keywords: Upper Uruguay River. Funerary deposit. Guarani archaeological unit.

CARBONERA, Mirian; SILVA, Sérgio Francisco Serafim Monteiro da; LOURDEAU, Antoine; HERBERTS, Ana Lucia; KUCZKOVSKI, Francieli; HATTÉ, Christine; FONTUGNE, Michel; ONGHERO, André Luiz; BRIZOLA, Jéssica Pedroso; SANTOS, Marcos César Pereira. Uma deposição funerária Guarani no alto rio Uruguai, Santa Catarina: escavação e obtenção de dados dos perfis funerário e biológico. Boletim do Museu Paraense Emílio Goeldi. Ciências Humanas, v. 13, n. 3, p. 625-644, set.-dez. 2018. DOI: http://dx.doi.org/10.1590/1981.81222018000300008. Autora para correspondência: Mirian Carbonera. Universidade Comunitária da Região de Chapecó. Centro de Memória do Oeste de Santa Catarina. Rua Líbano, 111D. Chapecó, SC, Brasil. CEP 89805-510 (mirianc@unochapeco.edu.br). ORCID: https://orcid.org/00000003-3651-1438.

Recebido em 22/12/2017

Aprovado em 26/06/2018
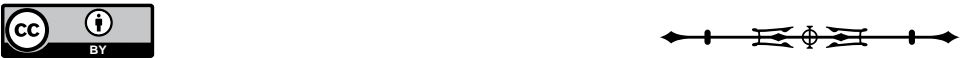


\section{INTRODUÇÃO}

Os grupos relacionados à unidade arqueológica Guarani ocuparam amplas áreas da bacia do rio da Prata, assim como o litoral Atlântico do Sul do Brasil. No alto rio Uruguai, diferentes autores têm registrado sítios desta unidade, a exemplo de Schmitz (1957), Rohr (1966), Piazza (1969, 1971), Miller (1969, 1971), Chmyz e Piazza (1967), Goulart (1985a, 1985b, 1985c, 1997), Silva, O., et al. (1998), Lavina (2004), Caldarelli (2010) e De Masi (2012).

Com o objetivo de colaborar para o entendimento do comportamento mortuário dessa unidade arqueológica, apresentam-se os dados da escavação de uma deposição funerária com corpo dentro de recipiente cerâmico usado como urna funerária. $\bigcirc$ estudo desta deposição foi realizado no âmbito do Projeto "Povoamentos pré-históricos do alto rio Uruguai" (POPARU), missão franco-brasileira, iniciado em 2013, cujo propósito principal é produzir conhecimento sobre os povoamentos pré-históricos do Sul do Brasil. A estrutura funerária foi encontrada no setor 2 do sítio $\mathrm{ACH}$ LP-07, que se localiza no município de Águas de Chapecó, Santa Catarina, na margem direita do rio Uruguai, em uma curva do rio conhecida como Volta Grande, próxima à foz do rio Chapecó (Figura 1).

Nessa mesma região, durante as pesquisas realizadas por Caldarelli (2010) para implantação da Usina Hidrelétrica (UHE) Foz do Chapecó, foram descritos ao menos seis sepultamentos em recipientes cerâmicos usados como urnas funerárias, relacionados à unidade Guarani. Estes sepultamentos, similares ao analisado aqui, foram interpretados e discutidos por Müller e Souza (2011).

A deposição funerária escavada no sítio ACH-LP-07 é formada por dois vasilhames cerâmicos inseridos em uma cova, sendo um recipiente utilizado como urna para acomodar o cadáver e outro empregado como tampa, ambos apresentando decoração plástica corrugada. As análises permitiram inferir que o sepultamento era primário, ou seja, uma deposição simples, caracterizada por enterramento ou inumação primária (Sprague, 2005), contendo um indivíduo adulto.
Apresentaremos a seguir o histórico da pesquisa, os dados de campo e de laboratório, bem como os resultados obtidos, fazendo uma análise a partir do contexto arqueológico local e regional. Destacaremos a importância desse achado para o conhecimento das sociedades da unidade Guarani, do Holoceno recente do alto rio Uruguai e, de forma mais ampla, da bacia do rio da Prata.

\section{O SÍTIO ARQUEOLÓGICO ACH-LP-07 E A ESCAVAÇÃO DA DEPOSIÇÃO FUNERÁRIA}

$\mathrm{Na}$ segunda etapa de campo da missão francobrasileira ocorrida no ano de 2014, deu-se início à escavação do sítio ACH-LP-07, o qual é a céu aberto, multicomponencial, com ocupações pré-ceramistas, ceramistas e históricas. Ele está localizado em uma plataforma elevada (várzea), à margem direita do rio Uruguai, a uma altitude que varia entre 225 e 237 m, a aproximadamente $1 \mathrm{~km}$ à jusante do barramento da UHE Foz do Chapecó. Encontra-se inserido em uma área de $400 \mathrm{~m}$ de comprimento por $50 \mathrm{~m}$ de largura, no máximo. Essa porção da margem do rio foi poupada dos trabalhos de terraplanagem - empreendidos durante a construção da usina - e do posterior aterramento com vistas à implantação de açudes para reprodução de peixes, sendo parcialmente preservado o depósito sedimentar original, bem como os vestígios arqueológicos lá encontrados. Duas áreas estão sendo escavadas, o setor 2 e o setor 1 , sendo o último exclusivamente pré-cerâmico, com uma antiguidade de mais de 11 mil AP. O setor 2, localizado a S $27^{\circ} 07.797^{\prime}$ W $053^{\circ} 02.388^{\prime}$, foi demarcado a partir da localização espacial da deposição funerária aqui analisada, que aflorava na superfície (Figuras 1 a 3) (Lourdeau et al., 2016). A preservação dos vestígios do nível de ocupação referente à unidade arqueológica Guarani, no sítio $\mathrm{ACH}$ LP-07, foi bastante prejudicada. Além dos fatores ligados à construção da barragem já mencionados, ressaltam-se os trabalhos agrícolas empreendidos antes da implantação da usina hidrelétrica, somados a questões naturais, como alterações por fitoturbação, acidez do solo e umidade.

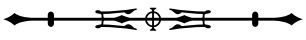


Em outras partes do sítio, além da deposição funerária situada no setor 2, é possível encontrar pequenas manchas de terra preta e principalmente fragmentos de cerâmica e de materiais líticos.
A escavação da deposição funerária foi efetuada em uma área quadriculada de $25 \mathrm{~m}^{2}$, localizada no entorno da estrutura, com quadras de $1 \times 1 \mathrm{~m}$; a deposição situava-se nas quadras 3C, 3D e 4C. O procedimento da escavação

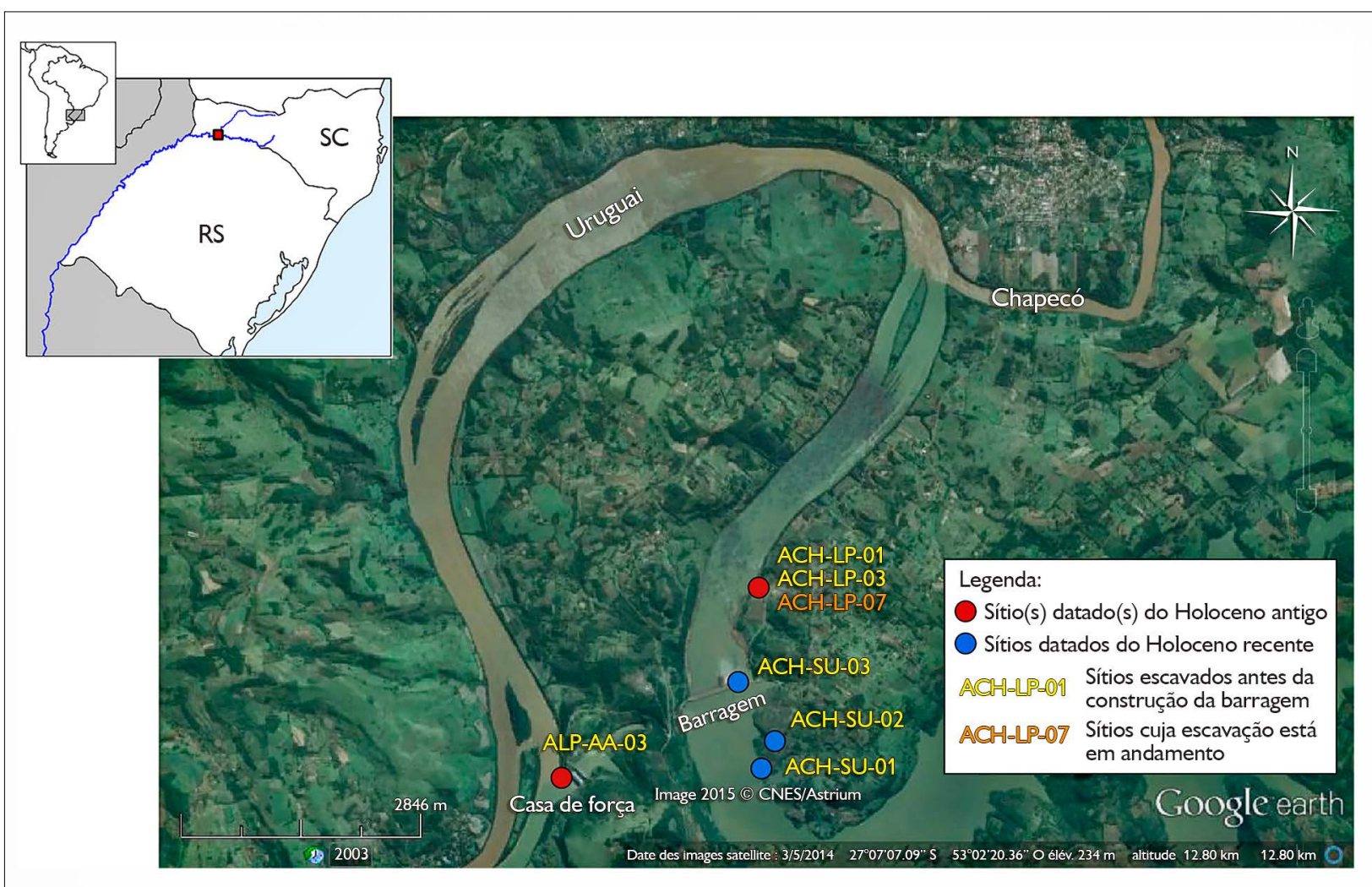

Figura 1. Mapa com a localização do sítio ACH-LP-07. Fonte: Lourdeau et al. (2016).

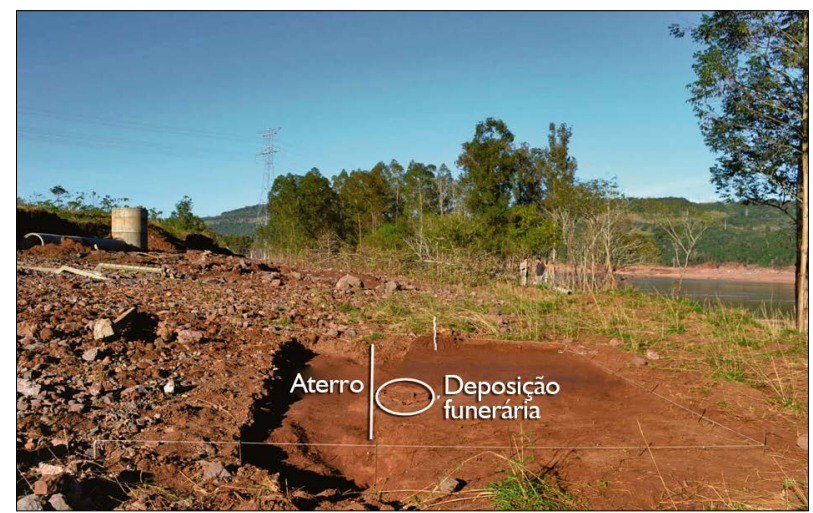

Figura 2. Sítio ACH-LP-07, setor 2, vista geral do contexto da deposição funerária durante a missão de 2014. Foto: Mirian Carbonera (2014)

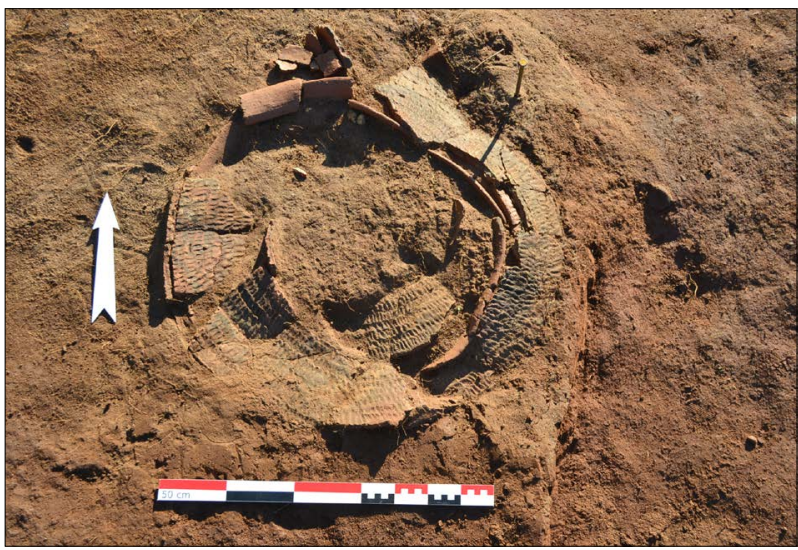

Figura 3. Fotografia vertical da deposição funerária. Foto: Mirian Carbonera (2014)

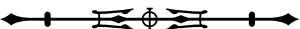


visou evidenciar os contextos estratigráfico e sedimentar associados à estrutura. Observou-se, em campo, a ausência de diferenças entre o sedimento ao redor da urna e o sedimento do resto do setor, por critérios de textura e de cor. $\mathrm{Na}$ impossibilidade de identificar e de delimitar a cova preparada para a inumação, registrou-se tudo por meio de fotografias verticais e oblíquas, conforme recomendado em Barker (2002). Decidiu-se, então, recuperar a estrutura funerária do sítio em forma de bloco, para, posteriormente, proceder a escavação do interior do recipiente, objetivando a retirada dos elementos ósseos e de materiais associados, sendo esta atividade realizada no laboratório do Centro de Memória do Oeste de Santa Catarina, da Universidade Comunitária da Região de Chapecó (CEOM/Unochapecó). Antes da remoção da estrutura, foram definidos e posicionados in loco três pontos de referência dentro do sistema de coordenadas cartesianas da escavação $(x, y, z)$, com o intuito de reposicionar, no laboratório, o bloco extraído, exatamente na orientação e inclinação originais. Para realizar o transporte da estrutura funerária do sítio até o laboratório, optou-se por manter o conteúdo interno e cerca de $5 \mathrm{~cm}$ de solo da matriz no entorno da estrutura, sendo fixados com filme plástico. Posteriormente, o bloco foi retirado e colocado em uma caixa de madeira, preenchida de materiais macios para estabilizar, firmar e amortecer o contato do bloco com a estrutura e o caixote. Apesar das dificuldades com a remoção e o transporte do bloco devido ao seu peso, a grande vantagem dessa estratégia foi a possibilidade de realizar a escavação interna da estrutura em laboratório, com maior controle e melhor proteção dos vestígios, já que os ossos poderiam estar muito deteriorados.

Além do controle do posicionamento tridimensional dos vestígios, cada procedimento realizado durante as decapagens foi registrado com fotografias e desenhos. Cada vestígio retirado recebeu um número na ficha de campo e, posteriormente, um número geral de inventário. Para proceder à escavação do sedimento, tanto da parte interna como da externa, o qual estava muito seco e compacto, foi necessário empregar borrifadores com água destilada. Utilizaram-se também ferramentas odontológicas para o sedimento, estecas apontadas de madeira e pincéis com cerdas naturais para ossos, cerâmicas e demais vestígios.

Primeiramente, foi realizada a remoção da parte interna, ou seja, a retirada dos fragmentos da tampa, do sedimento, de carvões, de ossos e de outros fragmentos de cerâmica que haviam se segmentado e caído no interior do bloco. Em relação aos ossos, optou-se pelo umedecimento gradativo, para que a retirada fosse menos prejudicial possível, tentando evitar ao máximo sua fragmentação. Em alguns casos, realizou-se a consolidação de poucos fragmentos fora da urna com uma solução de 20\% de paraloide (B72) em acetona PA. Procurou-se, quando possível, não remover os fragmentos estáveis da parte externa do recipiente cerâmico. Ao ser finalizada a remoção dos vestígios da parte interna, efetuou-se a escavação do restante dos fragmentos cerâmicos, especialmente da urna, ainda inserida na porção externa da matriz circundante que compunha o bloco. Vale ressaltar que a estrutura funerária apresentou perturbação por raízes e outros elementos, que também contribuíram para o processo de decomposição dos ossos.

A escavação da matriz de solo - ou da unidade de escavação - no interior da estrutura foi realizada por meio de decapagens por "[...] níveis artificiais [...]" (Fernández Martínez, 2000, p. 79, tradução nossa) de aproximadamente $5 \mathrm{~cm}$, técnica justificada pela invisibilidade macroscópica de níveis de sedimentos distintos dentro da matriz, de estrutura sedimentar natural, excetuando-se os ossos humanos. Acaso os ossos fossem considerados como 'unidades de escavação', a decapagem poderia ocorrer por 'níveis naturais', isto é, considerando-se exclusivamente a morfologia dos ossos. Inicialmente, retirou-se somente o sedimento e os fragmentos cerâmicos que haviam se depositado superficialmente, dentro dos intervalos de $5 \mathrm{~cm}$, na parte interna, em decorrência de processos tafonômicos antigos, possivelmente associados à ação da água e a outros agentes naturais e culturais não identificados in situ. 
Somente depois de completamente evidenciados, após as decapagens por níveis artificiais - considerando-se que alguns ossos apresentavam seus eixos longitudinais dispostos verticalmente ou obliquamente à base da vasilha e que as retiradas sequenciais do sedimento envolvente não possibilitavam a sua remoção -, foram retirados os ossos que se preservaram (Ubelaker, 1984; White; Folkens, 2005). Por fim, devido às intensas fragmentação e compactação do material, o bloco de sedimento contendo o crânio, localizado na base da urna, foi retirado inteiro e conservado desta forma, sendo, posteriormente, submetido à tomografia computadorizada (TC). Este bloco ainda não foi escavado. Também foram coletadas amostras de sedimento com restos de carvão, que estavam incrustados na parede do recipiente utilizado como urna. Nas Figuras 4 e 5, é possível observar a decapagem da parte interna da estrutura funerária, desde a superfície até a finalização.

Durante a escavação em laboratório, observou-se que, no decorrer da decapagem 5, tornaram-se visíveis

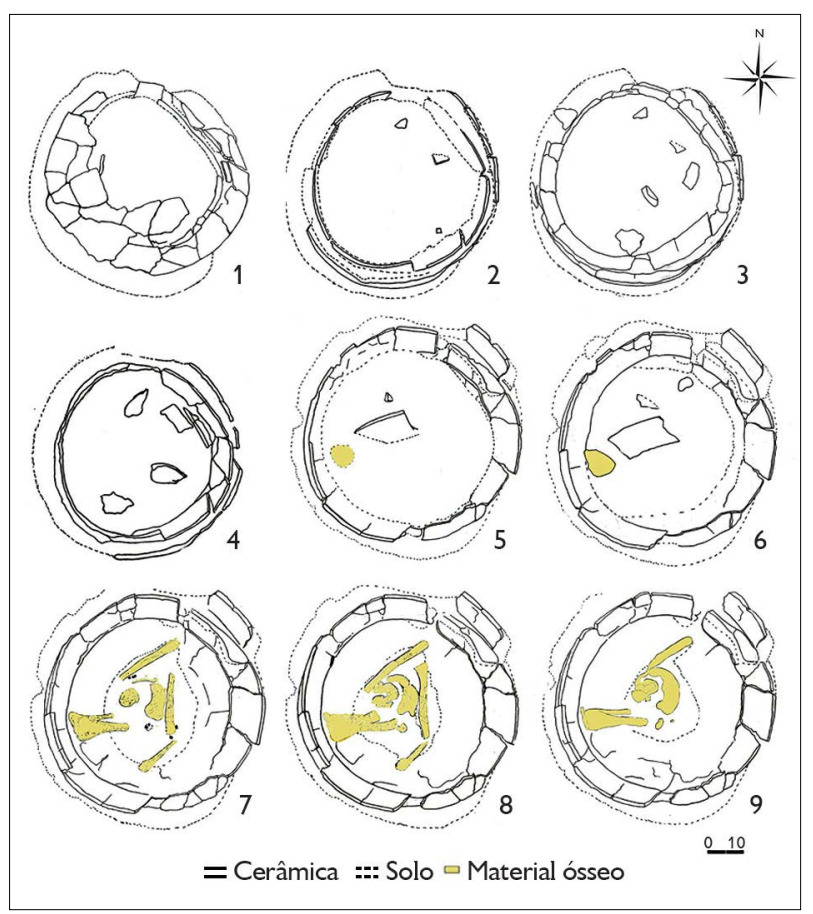

Figura 4. Representação das sucessivas decapagens desde a superfície até a retirada do bloco final. Desenhos: Regiane Eberts (2016).

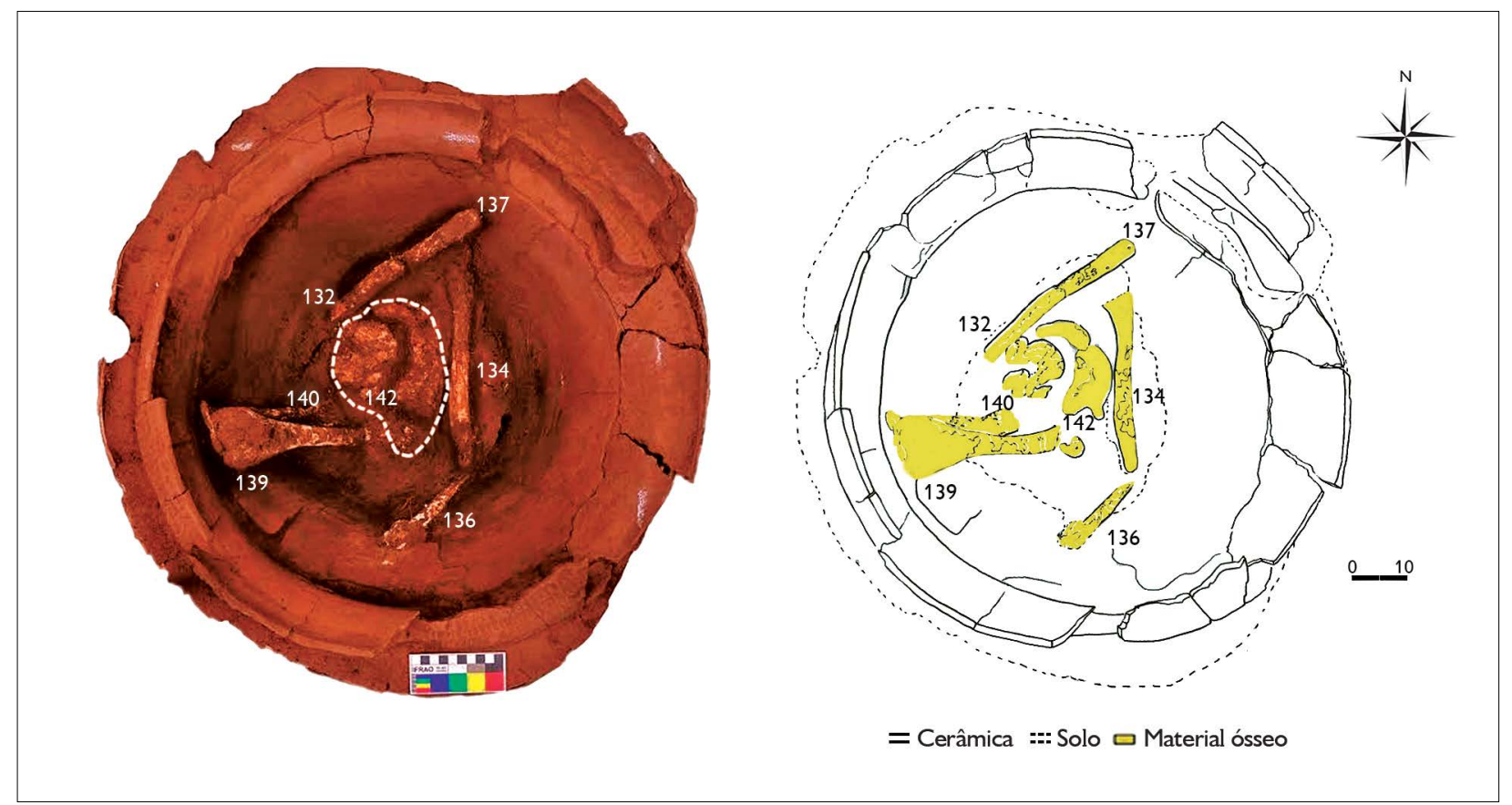

Figura 5. Visão geral dos remanescentes ósseos in loco na decapagem 7. Legendas: $137=$ terço proximal da tíbia direita; $132=$ terço distal da tíbia direita; 140 = tíbia esquerda (ao lado da fíbula esquerda); 139 = fêmur esquerdo; 134 = fêmur direito; 136 = úmero esquerdo; 142 = bloco com o crânio e a mandíbula articulados. Fonte: elaborada com base em Lourdeau et al. (2016). Desenho: Regiane Eberts (2016).

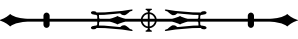


porções de ossos longos dos membros inferiores, indicadores da posição do corpo (sentado e fletido) (Figura 4, desenho 5). Tratam-se dos ossos do esqueleto que se preservaram em 'conexão anatômica'.

Os remanescentes ósseos são uma parcela ínfima do registro arqueológico. Convém observar que, mesmo quando encontrados pelos arqueólogos, eles apresentam limitações, já que sofreram diferentes processos e mudanças post-mortem (Müller; Souza, 2011; Silva, S., 2014; White; Folkens, 2005). Estes processos envolvem remodelações associadas às modificações tafonômicas, que podem ser causadas por agentes físicos, incluindo remodelações químicas provocadas pelas variações de temperatura e de umidade, por processos pedológicos e hidrológicos, bem como por perturbação por animais e por plantas, por exemplo (White; Folkens, 2005). No caso da deposição do setor 2 do sítio ACH-LP-07, a fragmentação da tampa e/ou o seu movimento permitiu a entrada de sedimento, assim como a ação de raízes que provocaram a degradação do esqueleto e a parcial desconexão anatômica entre os ossos. Umidade, plantas e microrganismos presentes no solo contribuíram para a decomposição dos ossos, tornando-os friáveis no momento da escavação (Figuras 6 e 7).

A designação de sepultamento primário (Ubelaker, 1984; White; Folkens, 2005; Duday, 2009) ou de deposição simples (Sprague, 2005) está fundamentada principalmente pela presença de 'conexão anatômica' (articulation) entre os principais ossos do esqueleto, como fêmures, tíbias, fíbulas, úmeros e crânio/ mandíbula. Após a decapagem do esqueleto, observou-se que o crânio estava depositado sobre os ossos dos quadris,

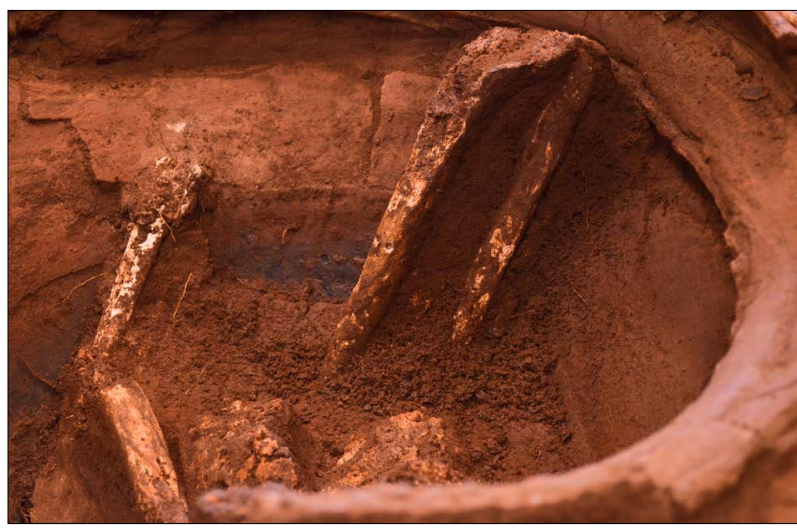

Figura 6. Remanescentes ósseos degradados, assim como pequenas raízes e sedimento, fragmentação da urna e parede interna enegrecida. Fêmur e tíbia esquerdos (à direita) e úmero esquerdo (à esquerda). Foto: Mirian Carbonera (2016).

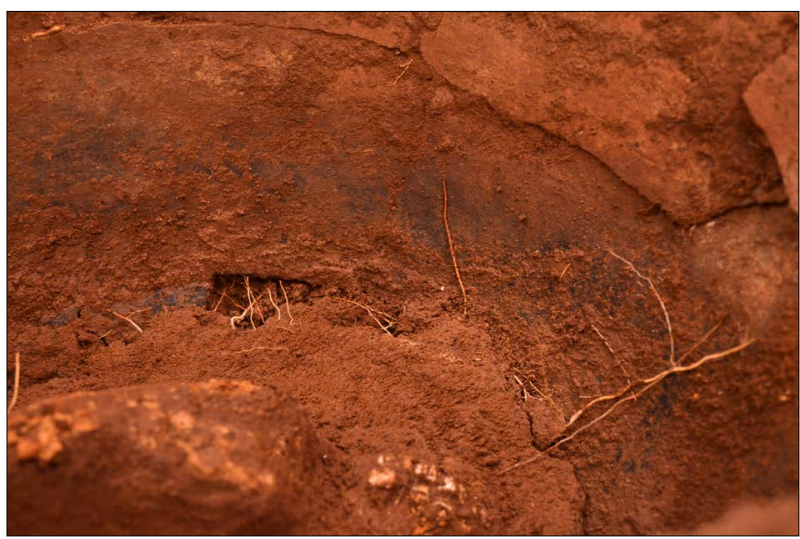

Figura 7. Remanescentes ósseos do crânio degradados e dentes (primeiro plano), assim como raízes e sedimento, além da fragmentação da urna e parede interna enegrecida. Foto: Mirian Carbonera (2016)

disposto com a superfície lateral direita sobre eles. Os ossos parietais e frontais encontravam-se esmagados, sob fragmento de cerâmica do recipiente utilizado como tampa².

O termo aqui adotado foi empregado por Ubelaker (1984), White e Folkens (2005), Sprague (2005) e Mays (2010) como 'articulation' ou mesmo em suas variações, incluindo os termos "semi-articulated", "partial articulation", "rearticulated", "disarticulated" e "disturbed" (Sprague, 2005, p. 29).

2 A presença do crânio, com mandíbula em conexão anatômica, na região dos ossos dos quadris e neste nível indica que houve espaço suficiente dentro do recipiente cerâmico para a decomposição e a desarticulação das vértebras cervicais e para a consequente queda do esqueleto da cabeça sobre o canal pélvico antes do preenchimento total da 'urna' com sedimento da matriz circundante e dos níveis superiores da abertura da 'tampa'. Na sequência dos processos de formação do depósito arqueológico, a presença do fragmento de 'tampa' imediatamente depositado sobre os ossos do crânio indica que houve espaço suficiente no vasilhame cerâmico para a sua queda e reposicionamento neste nível.

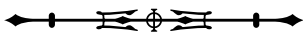


A maxila esquerda encontrava-se junto ao terço proximal do fêmur esquerdo. Existem vários vestígios de ossos compactados encontrados e mantidos em um bloco único, os quais, porém, estão comprometidos, devido ao avançado estado de decomposição óssea. Para se ter melhor ideia do bloco retirado com o crânio, foram realizadas imagens tomográficas $3 \mathrm{D}$ (TC3D), nas quais foi possível visualizar partes do esqueleto em blocos, sem intervenção invasiva (Figura 8).

Nestas imagens de tomografia do bloco retirado do fundo do recipiente cerâmico (Figura 8), é visível a matriz sedimentar em cinza médio e claro; em branco, observa-se o esmalte dentário; em cinza escuro e preto, são vistas as substâncias compacta e trabecular. Os ossos do esqueleto encontravam-se em conexão anatômica parcial $^{3}$, apresentando as seguintes características: a) manutenção da conexão anatômica entre o crânio e a mandíbula, indicada pela oclusão entre os dentes superiores e inferiores (Figuras 8B e 8C), com presença de esmagamento dos ossos do neurocrânio e do viscerocrânio (Figura 8), da conexão anatômica entre fêmur (Figura 5, número 139) e tíbia (Figura 5, número 140) esquerdos, no nível da epífise distal do fêmur e proximal da tíbia. Nessa relação, inclui-se a fíbula esquerda, muito decomposta, também verticalizada e paralela à tíbia, em conexão anatômica parcial, com leve deslocamento do terço proximal. Os terços proximais e distais da tíbia e da fíbula esquerdas coincidem com posições compatíveis com a manutenção da conexão anatômica entre elas; b) a relação de posição e de localização do úmero esquerdo, verticalizado e com a epífise proximal para cima, e distal para baixo, em direção ao fundo do recipiente, indica presença de manutenção temporária da conexão anatômica deste osso com os ossos cíngulo dos membros superiores, totalmente decompostos, não mais observáveis durante a escavação. Em decorrência do mau estado de conservação do esqueleto, com acelerada decomposição da substância compacta e especificamente da substância trabecular dos ossos, existe um problema de identificação precisa do úmero, da tíbia, do fêmur e da fíbula direitos.

Entre os dados do perfil biológico (DiGangi; Moore, 2013), foi inferida a idade do indivíduo escavado após análise das imagens de tomografia do crânio. Conforme Brothwell (1981), Ubelaker (1984) e White e Folkens (2005), a presença de terceiros molares erupcionados é indicativa de idade aproximada de 21 anos ou mais. Sobre esse dado especificamente, o fechamento das linhas epifisiais, os aspectos da superfície auricular, a sínfise púbica, as suturas cranianas e a extremidade esternal de costela não puderam ser observados ou avaliados de forma conjunta.

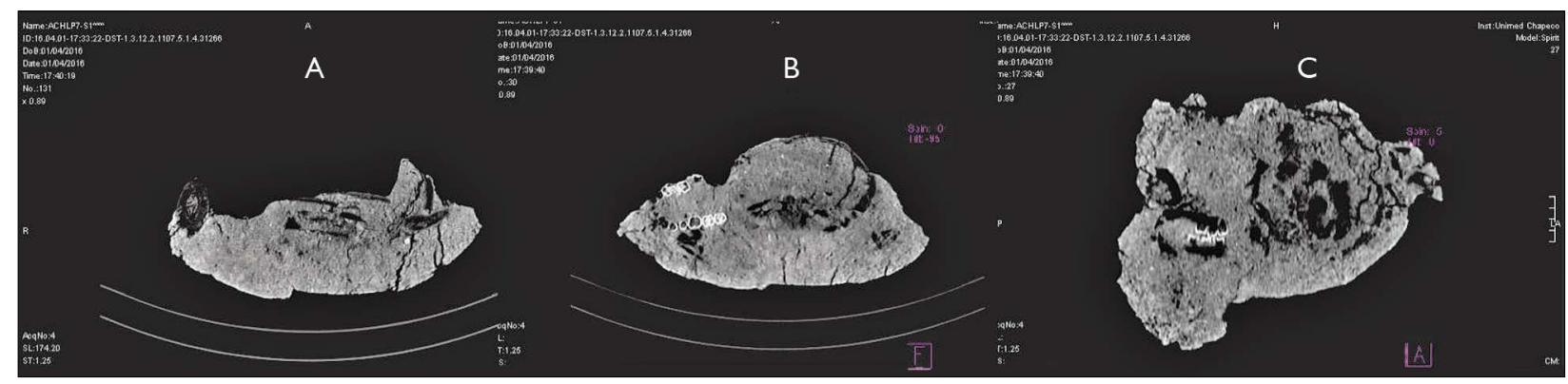

Figura 8. Bloco contendo o crânio retirado do fundo do recipiente cerâmico: A) crânio; B) crânio visto pela base; C) crânio visto pela norma lateral esquerda. Fonte: Hospital Unimed Chapecó (2016).

3 Este termo refere-se às denominações sugeridas por Sprague (2005, p. 29) como "[...] partial articulation [...]" e "[...] semi-articulated (semi-articulosis, semi-disarticulated) [...]", substituídas aqui por 'conexão anatômica parcial'.

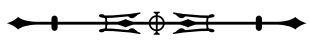


Quanto ao sexo, não estavam preservados os caracteres dimórficos, como aqueles descritos para o crânio e a mandíbula, para os ossos dos quadris ou para as cabeças de úmero, de rádio e de fêmur (Buikstra; Ubelaker, 1994; White; Folkens, 2005; Bass, 2005). Não foram realizadas aproximações de comprimentos máximos dos ossos longos a partir de seus fragmentos (Steele; Bramblett, 1988) para a estimativa da estatura ou para o registro de remodelações ósseas decorrentes de doenças, de traumas e de anomalias. A estimativa da estatura, dos dados paleopatológicos, da análise morfométrica comparada das diáfises preservadas, dos estudos histológicos e biomoleculares (DiGangi; Moore, 2013) ainda deve ser objeto de um artigo, após a reconstituição dos fragmentos e a recuperação sistemática do crânio, de dentes, de ossos da pelve e de amostras para datação (dente e parte petrosa do temporal), ainda mantidos em bloco para a sua preservação.

\section{HIPÓTESES PARA A INTERPRETAÇÃO SOBRE O CONTEXTO ARQUEOLÓGICO DOS OSSOS DO ESQUELETO NO RECIPIENTE CERÂMICO}

Sobre o aspecto final da disposição dos ossos, sugere-se a seguinte hipótese: a tíbia direita (Figura 5, terço distal, número 132, e terço proximal, número 137, separados por quebra e reposicionados durante a penetração de sedimento na urna) e o fêmur direito (Figura 5, número 134) apresentavam manutenção da conexão anatômica entre eles quando o maior osso, ainda articulado ao osso do quadril direito (decomposto), sofreu um giro sobre os ossos já sem conexão anatômica do tronco, resultando na acomodação do seu terço distal junto do terço distal do úmero esquerdo (Figura 5, número 136), e a diáfise com sua face anterior voltada para a base do crânio. A identificação precisa demanda análise comparada morfoscópica e morfométrica dos acidentes anatômicos ainda preservados nos fragmentos de diáfises e de epífises (Figura 5, números 132, 134 e 137).

A queda do crânio, com o decorrer do processo de decomposição do corpo, teria resultado no deslocamento moderado da tíbia direita e na perda da conexão anatômica da epífise distal e consequente rotação do eixo longitudinal do fêmur direito. Este osso longo teria sofrido a maior mobilidade ainda antes do preenchimento da urna com o sedimento local, possivelmente pela perda de conexão anatômica com a tíbia e pela consequente rotação da cabeça no acetábulo. Posteriormente, durante o preenchimento e a reacomodação sedimentar no interior da urna e o início da decomposição óssea, a tíbia teria se fragmentado e os demais ossos, sofrido esmagamentos e perda acentuada das suas substâncias compactas e esponjosas. A invisibilidade da grande maioria dos ossos do esqueleto axial e dos pés e das mãos no contexto da escavação deve-se à sua decomposição muito severa.

A perda da conexão anatômica do crânio (com a mandíbula) em relação às vértebras cervicais ( $\mathrm{C} 1$, atlas, e C2, axis) é relativamente comum em esqueletos de sepultamentos primários em urnas, cestos ou covas, principalmente quando o cadáver é depositado sentado (Castro et al., 2015; Solari et al., 2016). Após decorrido algum tempo da deposição do corpo, um novo espaço interno no recipiente (ou cova) se forma, resultante da decomposição e da perda dos tecidos moles do corpo, ocorrendo reacomodação dos ossos do esqueleto, com consequente perda (parcial ou total) das conexões anatômicas entre eles. A queda do crânio sobre os ossos dos quadris, durante a decomposição final do corpo - em um espaço vazio dentro da urna, ainda não totalmente preenchida pelos sedimentos da matriz de solo circundante -, ocasionou a perda da conexão anatômica entre outros ossos próximos, como se observou com o fêmur direito. A perda da conexão ou da articulação entre os ossos poderia ser minimizada nos casos de rápido preenchimento do interior da urna com sedimentos externos, em decorrência de fatores tafonômicos mais imediatos ao momento da deposição funerária.

Foi observada a manutenção da conexão anatômica entre fêmur (139), tíbia (140) e fíbula esquerdos (muito decomposta). Observou-se a perda da conexão anatômica 
entre os remanescentes de ossos longos do membro inferior direito (denominados de tíbia, números 132 e 137, e de fêmur, número 134). Não foi observada, na reconstrução oferecida pelas imagens tomográficas, a manutenção da conexão anatômica, especificamente entre as cabeças dos fêmures e os acetábulos dos ossos dos quadris, embora os eixos destes ossos longos e de seus terços proximais indicassem essa conexão. É possível que a cabeça do fêmur direito estivesse ligeiramente deslocada do acetábulo esquerdo.

$\bigcirc$ úmero esquerdo encontrava-se verticalizado, apresentando seu terço proximal em nível mais inferior ao da epífise distal do fêmur esquerdo. O eixo longitudinal dele encontrava-se em relação de paralelismo com o eixo longitudinal do fêmur esquerdo, com leve inclinação lateral. $\bigcirc$ úmero direito e os demais ossos dos braços, severamente decompostos e não identificados claramente durante a escavação do recipiente, encontravam-se esmagados e depositados sob o fêmur direito e o crânio, com perda da manutenção de conexão anatômica do terço proximal do úmero.

Os ossos dos membros superiores, incluindo os rádios e as ulnas de ambos os lados, bem como o úmero direito, estavam sob o crânio e o fêmur direito deslocado e foram retirados em bloco. Entretanto, foram observadas secções transversais de diáfises, possivelmente pertencentes aos ossos metatarsais dos pés (Figuras 8B e 8C).

Ao final da escavação, o esqueleto estava representado por segmentos decompostos das diáfises dos fêmures, das tíbias, da fíbula esquerda, do úmero esquerdo, de porções do neurocrânio extremamente fragmentadas e reacomodadas por esmagamento resultante do peso do substrato e da fragilidade dos tecidos ósseos decompostos, de massas de ossos alveolares e de dentes remanescentes (observáveis durante a escavação e inseridos no bloco tomografado na Figura 8).

Por fim, os ossos de pés e de mãos, bem como da coluna vertebral, costelas, sacro, ossos dos quadris, esterno, clavículas, escápulas, úmero direito, ulnas, rádios e hioide não estavam visíveis, exceto as diáfises dos ossos dos metatarsos e dos metacarpos, observáveis nas imagens tomográficas (Figura 8). Assim, os indicadores do contexto arqueológico dos remanescentes denotaram que o esqueleto se encontrava articulado, em posição sentada, o que foi observado pela presença de conexões anatômicas persistentes (Duday, 2009) entre os ossos longos, especialmente dos membros inferiores. A mudança de posição de alguns ossos resulta da decomposição do corpo, associada à perda da conexão anatômica entre eles e à presença de espaços vazios no interior do recipiente. Nesse caso, para White e Folkens (2005, p. 15), esses ossos estão em um "[...] anatomically natural arrangement [...]" ou propriamente em uma conexão anatômica (Duday, 2009), característica de um sepultamento primário. Ainda, a limitação espacial dentro do recipiente cerâmico usado como urna corroborou a estabilização da posição de alguns ossos longos, que permaneceram em conexão anatômica em relação aos demais ossos do esqueleto e ficaram apoiados nas paredes internas do bojo do recipiente. A posição do corpo, mesmo por causa das limitações do espaço interno do recipiente, deve ter sido a hiperfletida, vertical (sentado), com eixos longitudinais entre fêmures e tíbias/ fíbulas, com ângulos menores do que $35^{\circ}$, e braços dispostos entre as pernas, com a face junto dos joelhos. Essa posição foi também observada por Pallestrini (1969), na escavação, feita em laboratório, de uma urna com aproximação cultural Guarani, coletada no sítio Fonseca, em São Paulo, porção centro-meridional do Brasil, datada entre 400 e $500 \mathrm{AP}$.

\section{OS CONTEXTOS CRONOLÓGICO E ARQUEOLÓGICO E AS CARACTERÍSTICAS TECNOMORFOLÓGICAS DOS VASILHAMES CERÂMICOS}

Após a retirada dos ossos e a escavação completa dos vasilhames cerâmicos, foi realizada a curadoria dos 
fragmentos; na sequência, foi feita a reconstituição ${ }^{4}$, a fim de obter-se a forma original dos vasilhames (Figura 9). Ao final, foi possível observar as características tecnológicas e morfológicas dos recipientes. $\bigcirc$ vaso utilizado como urna possui diâmetro de boca de $58 \mathrm{~cm}$, altura de $53 \mathrm{~cm}$, espessura média de $10 \mathrm{~mm}$ e circunferência do ombro inferior de $192 \mathrm{~cm}$. Apresenta queima do tipo oxidada incompleta, com acabamento corrugado na face externa, borda extrovertida, lábio plano e arredondado, duplo ombro escalonado e formato cônico. Uma análise macroscópica da pasta indica grãos de areia, chamote e óxidos de ferro. A tipologia da vasilha é forma fechada de contorno complexo e proporção funda.

Já o recipiente utilizado como tampa possui diâmetro de boca de $65 \mathrm{~cm}$, espessura média de $10 \mathrm{~mm}$ e circunferência da inflexão de 203 cm. A altura sem a base é de $26 \mathrm{~cm}$, já a altura estimada foi de $36 \mathrm{~cm}$, uma vez que a base e a parte do bojo inferior não foram encontradas, talvez por provavelmente terem sido levadas pela água da enchente que expôs o conjunto. A queima é do tipo oxidada incompleta e o corrugado foi empregado como acabamento de superfície externa. A borda é direta, com inclinação de $100^{\circ}$, e apresenta formato de meia esfera. $\mathrm{Na}$ análise macroscópica da pasta, observam-se grãos de areia, chamote e óxidos de ferro. A tipologia desta vasilha é fechada de contorno simples e proporção funda.

A reconstituição permitiu que fosse obtida a forma completa do vasilhame utilizado como urna ${ }^{5}$, possibilitando, assim, melhor interpretação desse utensílio em seu contexto social. Antes de fazer parte do contexto funerário, o vaso
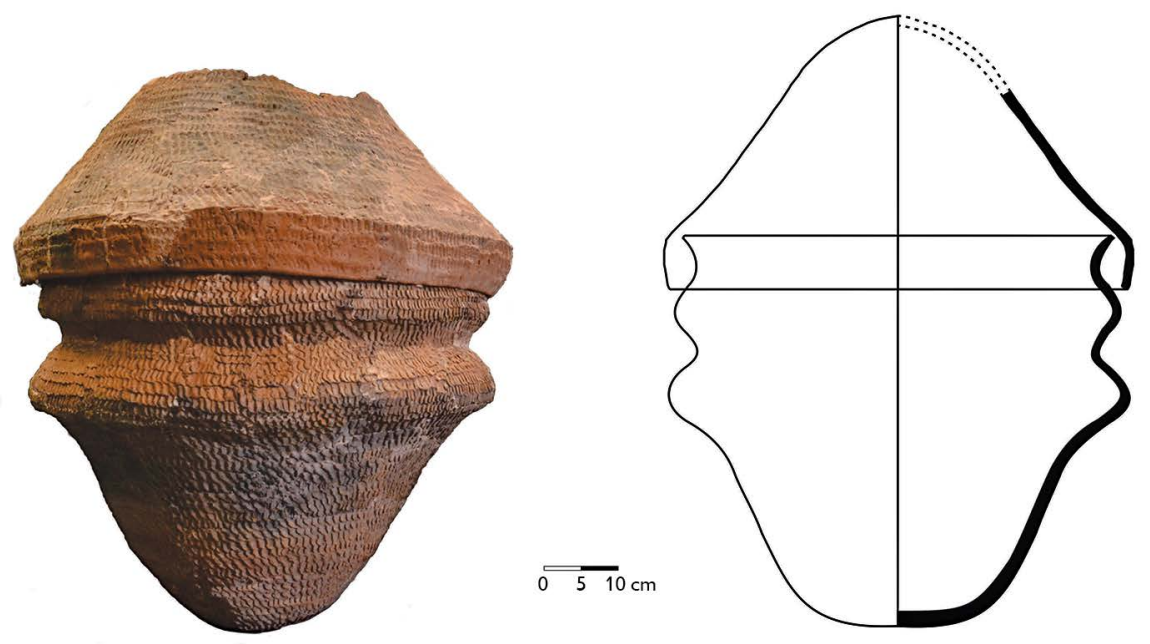

Figura 9. Reconstituição tecnomorfológica dos recipientes utilizados como urna e tampa. Fonte: Lourdeau et al. (2016).

\footnotetext{
4 Os fragmentos pertencentes aos recipientes foram inicialmente higienizados e inventariados. Em seguida, foram reunidos para reconstituição dos recipientes, a fim de que, assim, fossem obtidas as formas da tampa e da urna. Os fragmentos a serem colados foram limpos nas superfícies de quebra com acetona PA. Posteriormente, foi aplicada superficialmente uma camada de Primal como selante; depois, o adesivo paraloid (B72). Depois que os fragmentos foram colados, utilizaram-se fita e tecidos para secagem do adesivo, com o objetivo de manter a estrutura firme, a fim de não ocorrer a movimentação dos fragmentos. As tiras de fita adesiva neutra e o tecido que foram usados para fixar temporariamente os fragmentos em processo de colagem foram removidos após a secagem completa do adesivo. Nas partes faltantes de grandes proporções, o preenchimento inicial foi feito com tela plástica, porque ela contribui para manter a camada de gesso, colocada em sequência. A parte final compreendeu o preenchimento de todas as partes faltantes com gesso pigmentado. $\bigcirc$ acabamento consistiu em retirar o excesso de gesso das partes interna e externa, e fazer a limpeza dos recipientes com uma esponja úmida.

5 Para Müller e Souza (2011, p. 174), o termo "[...] urna funerária [...]" só pode ser utilizado quando comprovada a relação da cerâmica com o sepultamento ou com vasilhames de diferentes formas e tamanhos utilizados durante o ciclo funerário.
}

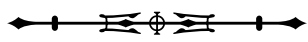


cerâmico foi empregado como recipiente utilitário, destinado para o cozimento no fogo. Essa inferência é feita com base na mancha enegrecida, observada na face interna do recipiente, que se estende da base até aproximadamente $22 \mathrm{~cm}$ de altura do bojo; nota-se também a presença de pontos de acresções com fuligem, indicando seu uso anterior para cozimento (Figuras 6, 7 e 10). Entretanto, durante a escavação e na etapa de reconstituição do vaso, não foi possível identificar qualquer tipo de quebra, rachadura ou marca que remetesse a um possível motivo de descarte de uso doméstico para reutilização como urna funerária. A face externa também apresenta manchas escuras na porção mesial do bojo (Figuras 9 e 10), as quais estão em posição distinta das observadas na face interna. Muito provavelmente elas são marcas das rochas que serviram de apoio quando o vaso era utilizado no fogo. Quanto ao recipiente utilizado como tampa, infelizmente, não foi possível encontrar sua base. A parte restante não apresentou manchas escuras, entretanto, pequenos pontos de fuligem são visíveis na face externa.

Um estudo etnoarqueológico com os Kalinga foi desenvolvido por Skibo (1992). O autor observou que os diferentes tipos de alimentos e suas respectivas formas de cozimento deixam marcas distintas na cerâmica.
Por exemplo, no cozimento de alimentos pastosos, como o arroz, é comum que ocorra a carbonização no fundo da panela, em razão do ressecamento da água. No tocante à determinação da função dos vasos, as acresções na superfície cerâmica podem se apresentar de duas formas gerais: como depósitos de carvão que resultam do cozimento sobre fogo aberto e como resíduos deixados por um conteúdo (Skibo, 1992). Normalmente, segundo o autor, a presença de fuligem é usada de forma frequente para discriminar os vasos de cozimento. Além disso, de acordo com Skibo (1992), o uso pretendido de um recipiente cerâmico não é sempre igual ao uso atual. Mencione-se como exemplo disso o fato de que, entre os Kalinga, se um pote de cozimento de arroz de tamanho apropriado não estiver disponível, um pote que era utilizado para preparar vegetais ou carne pode ser empregado para tal função. O trabalho de Skibo (1992) contribui para a reflexão sobre as possíveis adaptações realizadas pelos grupos humanos da unidade arqueológica Guarani, na busca de alternativas para a resolução de problemas diários, e também sobre como os vasilhames confeccionados com funções primárias de armazenar, de cozinhar ou de servir poderiam ser posteriormente empregados para funções secundárias, como urnas, dentro dos ciclos funerários.
\# Manchas enegrecidas na face interna

|| Manchas enegrecidas na face externa
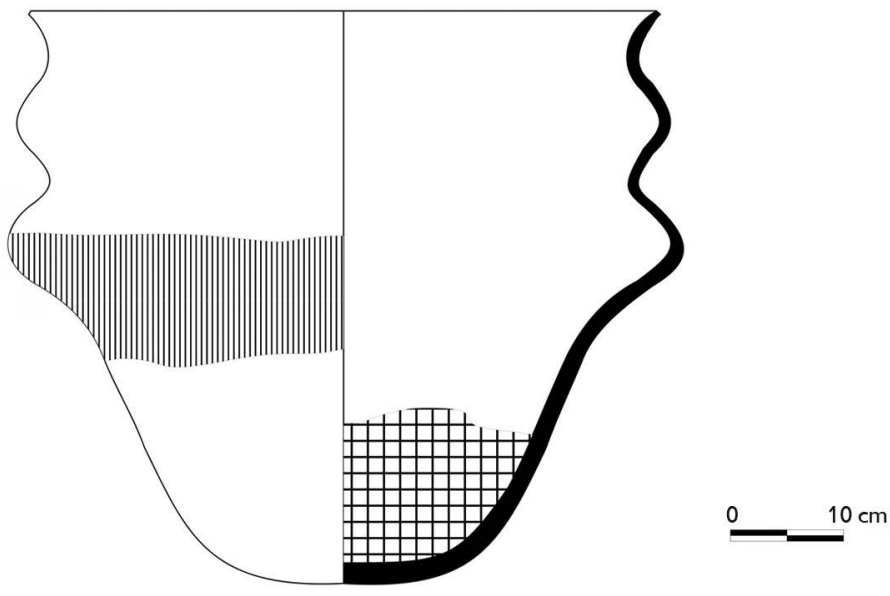

Figura 10. Vaso utilizado como urna, indicando a localização das manchas enegrecidas nas faces interna e externa. Desenho: Lucas Camargo (2017).

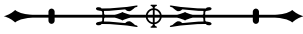


Além disso, La Salvia e Brochado (1989) apontam que as vasilhas da subtradição Guarani com base conoidal ou arredondada, bojo saliente, borda côncava, reta ou extrovertida e boca restringida teriam como principal função o cozimento de alimentos ao fogo.

Por sua vez, Müller e Souza (2011) colaboram para a hipótese de que os Guarani não confeccionavam cerâmica especialmente para ser usada como urnas funerárias, apontando para o uso de recipientes que já não podiam ser empregados nas tarefas diárias, por apresentarem rachaduras ou alguma parte faltante. Segundo as autoras, as "[...] 'urnas funerárias' Guarani, enquanto recipientes específicos não existem. Sua existência tem sido confirmada, no entanto, enquanto função" (Müller; Souza, 2011, p. 174).

As práticas mortuárias fazem parte dos sistemas sociais dos grupos humanos, sendo o sepultamento elemento de um funeral, o qual, por sua vez, parte de um conjunto de rituais pelos quais os vivos relacionam-se com a morte. Os rituais expressam símbolos, normas e costumes (Castro et al., 2015).

É crescente o número de trabalhos interdisciplinares levando em consideração dados etnohistóricos e etnográficos como importantes ferramentas conceituais e metodológicas para investigar profundamente os processos históricos de longa duração dos Guarani antes da conquista europeia (Noelli, 1993; Bonomo et al., 2015). No entanto, segundo Rizzardo (2017), estes dados precisam ser analisados com cautela, tendo em vista o contexto em que foram escritos, já que os cronistas europeus utilizavam filtros ocidentais para descrever os grupos indígenas. Os documentos etnohistóricos são raros para a região estudada, exceto por uma breve menção do início do período colonial, que atesta a presença Guarani, mas não detalha informações sobre deposições funerárias. Esse relato foi realizado pelo militar alemão Ulrich Schmidel, entre 1552 e 1553, que atravessou o rio Peperi-Guaçu e chegou à margem direita do rio Uruguai, aproximadamente na região do atual município de Palmitos, Santa Catarina. Segundo a interpretação de Maack (1968), Ulrich Schmidel encontrou uma povoação de indígenas da nação 'Biessaie' nesse local (Mbiazais - Mbyãs = Guarani).

Em razão da organização das tribos tupi-guaranis em grupos extensos e grandes famílias, César (1977) aponta como essas sociedades, estreitamente unidas pelas grandes famílias, importavam-se com os sepultamentos de seus falecidos. Isso explica, segundo esse autor, o cuidado de preparar os mortos, de preservar o cadáver do contato com a terra, mas, principalmente, de "[...] protegê-lo contra maus espíritos, do mundo dos vivos e de facilitar a viagem além-túmulo" (César, 1977, p. 27). Para César (1977), os Guarani deveriam utilizar outras formas de enterro para além do primário (o corpo colocado sem demora na urna) e do secundário (os ossos desenterrados e colocados na urna).

A estrutura funerária aqui analisada é composta por um grande vaso cerâmico, utilizado como recipiente para acomodar o cadáver (urna), e por outro menor, como tampa, evidenciando, assim, o cuidado e a proteção do corpo para evitar o contato com a terra. Embora a estrutura tenha sido muito modificada por processos pós-deposicionais, as análises indicam deposição simples, sepultamento primário, de um único indivíduo adulto, com esqueleto articulado, corpo depositado sentado dentro do recipiente cerâmico, associado à cultura Guarani, sem remanescentes de acompanhamentos funerários não perecíveis.

A estrutura não foi ainda datada diretamente. Quatro datações por radiocarbono foram efetuadas no setor 2 (Lourdeau et al., 2016) (Tabela 1). No momento da escavação, próximo à deposição funerária, quase na superfície, duas manchas de cinzas foram localizadas. Um fragmento de carvão de cada mancha foi datado, sendo que os dois resultados apontaram uma data mediana de 1880 AD (105 \pm 30 yr BP 6 , Gif13118/SacA40195;

\footnotetext{
6 yr BP: years before present, anos antes do presente, 1950 por convenção.
} 
$115 \pm 30$ yr BP, Gif13119/SacA40196). Devido ao contexto histórico da região, tais datas não podem ser associadas à deposição funerária aqui estudada. As manchas decorrem provavelmente das atividades agrícolas dos habitantes atuais da região, podendo ser marcas de estacas queimadas.

No setor 2 do sítio ACH-LP-07, ao redor da urna, um nível arqueológico (nível 1) foi encontrado, exclusivamente composto por material lítico, sem evidências de ligação com a unidade arqueológica Guarani e aparentemente mais antigo (Lourdeau et al., 2016). Até $\mathrm{o}$ ano de 2017, nenhuma estrutura de combustão foi encontrada nele, mas alguns pequenos carvões espalhados foram coletados. Dois deles foram datados, dando resultados muito diferentes $-395 \pm 30$ yr BP (Gif13160/SacA44482) e $7160 \pm 40$ yr BP (Gif13161/ SacA44483) -, ou seja, datas calibradas respectivas de 1455-1625 Cal AD (data mediana: 1547 AD) e 80157850 Cal AP. Pelo contexto regional, especificamente os resultados apresentados pelas pesquisas realizadas por
Caldarelli (2010), a data mais recente é coerente com uma ocupação Guarani, podendo esta corresponder à data da estrutura funerária. $O$ carvão datado seria, então, intrusivo no nível 1, talvez devido a uma perturbação consecutiva à escavação da fossa para o enterramento da urna. Já a data de aproximadamente 8.000 anos antes do presente poderia corresponder à idade do nível 1. No estado atual da pesquisa, privilegiamos então essa data de $395 \pm 30$ yr BP para a deposição funerária aqui estudada, salientando que se trata, por enquanto, de uma hipótese de trabalho, e não de uma idade definitiva.

Embora se localize já em período histórico, não se observou nenhum sinal de contato com o europeu. A localização dentro do contexto do sítio ACH-LP-07 permite o entendimento de que a área onde se encontrou a deposição funerária tenha sido destinada pela unidade Guarani para sepultamento, já que no entorno imediato não se evidenciou cerâmica, terra preta ou demais vestígios que indicariam, por exemplo, um local de moradia (Lourdeau et al., 2016).

Tabela 1. Datas radiocarbônicas por espectrometria de massa com aceleradores (AMS) obtidas a partir de carvões encontrados no setor 2 do sítio ACH-LP-07. As idades foram calibradas utilizando-se a curva de calibração ShCal13. Os intervalos das datas calibradas são dados com 2 sigma, ou seja, com um nível de confiança de 95,4\%.

\begin{tabular}{|c|c|c|c|c|}
\hline Número do laboratório & $\begin{array}{l}\text { Idade 14C } \\
\quad(y r \text { BP })\end{array}$ & $\begin{array}{l}\text { Intervalos de datas calibradas } \\
\qquad(2 \sigma)\end{array}$ & $\begin{array}{l}\text { Data calibrada } \\
\text { mediana }\end{array}$ & Observação \\
\hline Gif13160/SacA44482 & $395 \pm 40$ & $\begin{array}{l}{[1455 \mathrm{AD} ; 1525 \mathrm{AD}](42,8 \%)} \\
{[1535 \mathrm{AD} ; 1625 \mathrm{AD}](52,6 \%)}\end{array}$ & $1547 \mathrm{AD}$ & Carvão nível 1 \\
\hline Gif13161/SacA44483 & $7160 \pm 40$ & $\begin{array}{l}{[8015 \text { cal yr AP; } 7910 \text { cal yr AP] }(71,0 \%)} \\
{[7910 \text { cal yr AP; } 7850 \text { cal yr AP] }(24,4 \%)}\end{array}$ & $7947 \mathrm{cal} \mathrm{yr} \mathrm{AP}$ & Carvão nível 1 \\
\hline Gif13118/SacA40195 & $105 \pm 30$ & $\begin{array}{c}{[1695 \text { AD; } 1725 \text { AD] }(12,7 \%)} \\
{[1810 \mathrm{AD} ; 1840 \mathrm{AD}](22,8 \%)} \\
{[1840 \mathrm{AD} ; 1870 \mathrm{AD}](12,3 \%)} \\
{[1875 \mathrm{AD} ; . . .](47,6 \%)}\end{array}$ & $1866 \mathrm{AD}$ & $\begin{array}{l}\text { Mancha de cinza } \\
\text { recente }\end{array}$ \\
\hline Gif13119/SacA40196 & $115 \pm 30$ & $\begin{array}{c}{[1695 \text { AD; } 1725 \text { AD] }(13,9 \%)} \\
{[1805 \text { AD; } 1875 \text { AD }](35,6 \%)} \\
{[1875 \text { AD; ... }](45,9 \%)}\end{array}$ & $1862 A D$ & $\begin{array}{l}\text { Mancha de cinza } \\
\text { recente }\end{array}$ \\
\hline $\begin{array}{c}\text { Gif13118/SacA40195 e } \\
\text { Gif13119/SacA40196 } \\
\text { combinados }\end{array}$ & & $\begin{array}{c}{[1700 \mathrm{AD} ; 1725 \mathrm{AD}](10,6 \%)} \\
{[1810 \mathrm{AD} ; 1840 \mathrm{AD}](24,7 \%)} \\
{[1845 \mathrm{AD} ; 1870 \mathrm{AD}](9,6 \%)} \\
{[1880 \mathrm{AD} ; \ldots](50,5 \%)}\end{array}$ & $1880 \mathrm{AD}$ & $\begin{array}{l}\text { Mancha de cinza } \\
\text { recente }\end{array}$ \\
\hline
\end{tabular}




\section{ANÁLISE DA DEPOSIÇÃO FUNERÁRIA NO CONTEXTO REGIONAL}

Sepultamentos da unidade Guarani são tema comum na literatura arqueológica da bacia do rio da Prata, sejam as inumações diretas ou feitas em urnas. Um registro antigo foi realizado ainda no século XIX por Ambrossetti (1895). Somaram-se, desde então, muitos outros trabalhos que têm descrito e analisado esses achados: Lothrop (1931), Vignati (1941), Rohr (1966), Chmyz (1974), Lavina (1999), Kashimoto e Martins (2009), Klampt (2005), Pestana (2007), Müller e Souza (2011), Loponte et al. (2011), Mazza et al. (2016), entre outros. Compilações e análises dos dados arqueológicos relativos aos sepultamentos Tupi do período pré-contato e fontes etnográficas quinhentistas foram recentemente reunidas e discutidas por Rizzardo (2014, 2017) e Rizzardo e Schmitz (2015).

$\mathrm{Na}$ região do alto rio Uruguai, esses achados carecem de informações provenientes de escavações sistemáticas, já que, na maioria das vezes, os sepultamentos foram encontrados pelos moradores durante suas atividades de derrubada da floresta, de agricultura, de terraplanagens, de abertura de estradas, entre outras. Müller (2006) apontou como é comum os museus locais catarinenses salvaguardarem vestígios ósseos procedentes de enterramentos Guarani.

Desde fins do século XIX, são relatados achados de sepultamentos relacionados à unidade Guarani na região do alto Uruguai, como os descritos por Maximiliano Beschören ${ }^{7}$. Segundo o autor, nas proximidades da foz do rio Chapecó foram encontrados "[...] sob oito palmos de terra, grandes pratos de argila de 1 a 2 metros de diâmetro, com restos de ossos humanos, na maioria, reduzidos a pó" (Beschören, 1989 [1889], p. 51-52).

Na primeira metade do século $X X$, colonizadores europeus ou seus descendentes relatam ter encontrado vestígios arqueológicos ao iniciarem as atividades de cultivo, entre os materiais estão os sepultamentos em urnas. Koelln (2004) refere-se a um achado na margem direita do rio Uruguai, próximo à sede de Porto Feliz, hoje município de Mondaí, Santa Catarina:

\begin{abstract}
[...] descobriu-se o primeiro cemitério indígena com inúmeras urnas funerárias, em parte com esqueletos ainda bem conservados. Os mortos eram colocados de cócoras e, junto deles, pequenos vasos e tigelas, provavelmente contendo alimentos. Além disso, foram encontrados muitos instrumentos de pedra, armas, enfeites, pedras semi-preciosas [sic], algumas não existentes nesta região, inclusive pérolas de vidro, dado indícios de contato com brancos. Seguiram-se achados nas margens do Uruguai. Foram encontrados amplos cemitérios, onde os túmulos eram assinalados por pontas de pedra, altas urnas com colchetas para fixação das tampas e tigelas pintadas com desenhos quase clássicos. (Koelln, 2004, p. 20-21).
\end{abstract}

A frequência dos achados na região do alto rio Uruguai motivou as pesquisas de Schmitz (1957) e de Rohr (1966) no município de Itapiranga, Santa Catarina, na fronteira com a Argentina. Schmitz (1957) descreve um sítio da subtradição Guarani localizado na comunidade de Sede Capela, nas terras do pré-seminário jesuíta. Além de manchas de terra preta associadas a material arqueológico, ele relata que os moradores haviam desenterrado urnas neste local. Um pouco mais tarde, Rohr (1966) prospectou nessa região 53 sítios. Destes, em ao menos 33 foram feitas menções a achados de sepultamentos Guarani, através da constatação de igaçabas, que somavam mais de 160 peças:

Acima de 40 igaçabas continham restos de
esqueletos humanos. Houve, entre eles,
esqueletos completos, em bom estado de
conservação. Passando o arado pela primeira vez
'o solo estourava de panelas de bugre e os bois
afundavam com as pernas dentro delas', era esta
uma versão comum, ouvida por nós da boca dos
colonos mais antigos [...]. Escavamos ao todo cinco
urnas funerárias e recebemos outra por doação.
Três eram de grande tamanho; duas de tamanho

\footnotetext{
Maximiliano Beschören atuou na área como topógrafo. Na região, realizou expedições de levantamento a pedido do governo do Rio Grande do Sul, entre 1875 a 1887.
} 
médio e uma de tamanho pequeno. Tôdas [sic] possuíam tampa. Uma estava inteira; duas tinham apenas as bordas quebradas, mas os fragmentos todos presentes. (Rohr, 1966, p. 25-26).

O material resultante dessa prospecção, incluindo os sepultamentos encontrados ou recebidos de doação, foram enviados para o Museu do Homem do Sambaqui, de Florianópolis, Santa Catarina. Segundo Rohr (1966), das seis urnas descritas apenas uma foi deixada em Itapiranga, Santa Catarina, e, além dos vestígios ósseos, duas apresentavam também tembetás.

Miller (1969, 1971) e Piazza (1969, 1971) desenvolveram, por meio do Programa Nacional de Pesquisas Arqueológicas (PRONAPA), levantamentos às margens do rio Uruguai. Miller (1969) descreveu, para a margem esquerda do rio Uruguai, nos municípios de Tenente Portela e de Porto Lucena, ambos no Rio Grande do Sul, 36 sítios da fase Comandaí, relacionada à tradição Guarani, os quais apresentariam cemitérios com urnas, em alguns casos agrupadas em até quatro. No interior das urnas, segundo o autor, além de vestígios ósseos, constatou-se a presença de tembetás, de adornos confeccionados em pedra e osso e de outros potes pequenos (Miller, 1969). Ao efetuar levantamento na margem esquerda do rio Uruguai, descreveu, para os Guarani, as fases Itá e Ipira. Nos sítios de ambas as fases, são citados sepultamentos em urnas (Miller, 1971).

Por sua vez, Piazza (1969), ao prospectar a margem direita do rio Uruguai, entre os rios Peperi-Guaçu e Irani, menciona ter encontrado 40 sítios Guarani, relacionados à fase Mondaí. A descrição bastante superficial faz menção a urnas funerárias que se apresentavam em vasos predominantemente pintados e algumas vezes corrugados. A montante, em área mais próxima à formação do rio Uruguai, descreveu cemitérios somente para os sítios
Guarani da fase Itá (Piazza, 1971). Chmyz e Piazza (1967) relatam também sepultamentos em urnas nos municípios de Ipira e de Piratuba, em Santa Catarina.

Em pesquisa relacionada ao licenciamento ambiental da UHE Machadinho, arqueólogos da Pontifícia Universidade Católica do Rio Grande do Sul (PUC-RS) registraram o sítio U-467, na propriedade de Antônio Calderolli, município de Maximiliano de Almeida, Rio Grande do Sul, margem esquerda do rio Pelotas, caracterizado por mancha preta, que indica ocupação humana por razoável período de tempo e enterramento secundário Guarani em urna. Foram coletados no sítio fragmentos de cerâmica, lítico, ossos humanos, adornos, artefatos ósseos, vestígios de fauna e conchas. Junto à estrutura funerária, foram encontrados materiais de diferentes vasilhas. No entanto, como a estrutura havia sido perturbada por uma enorme raiz, além de outros processos tafonômicos, o material estava bastante fragmentado. Segundo os relatórios, além de ossos longos, de calota craniana, de dentes, parte de um tembetá de quartzo foi encontrada dentro da urna. Fragmentos de potes variados, dispostos já fragmentados para cobrir a abertura da urna, sugerem que eles teriam sido utilizados como tampa. No total, os fragmentos correspondem a cinco vasilhas distintas, e a morfologia do vaso utilizado como urna seria um cambuchí. Os ossos foram identificados como fragmentos de diáfise de fêmur, diáfise de úmero, fêmur, crânio, além dos dentes, indicando ser de indivíduo adulto ${ }^{8}$. A datação revelou uma idade de $210 \pm 80$ anos ${ }^{14} \mathrm{C}$. Ao que consta, essa pesquisa não foi publicada. Suas informações advêm de relatórios inéditos que se encontram no acervo do Setor de Arqueologia do Museu de Ciência e Tecnologia, da PUC-RS?.

Nas proximidades do sítio ACH-LP-07, foram encontradas outras estruturas funerárias (Figura 11). Mais informações sobre elas serão apresentados, devido à sua semelhança com o que é descrito neste trabalho.

\footnotetext{
8 Consta no relatório que a identificação dos ossos foi realizada pela professora Eugênia Cunha.

9 "Urna funerária no sítio U 467 Maximiliano de Almeida/RS". Relatório inédito. Acervo do Setor de Arqueologia, do Museu de Ciência e Tecnologia, da Pontifícia Universidade Católica do Rio Grande do Sul. Consultado em abr. 2016.
}

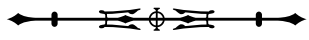




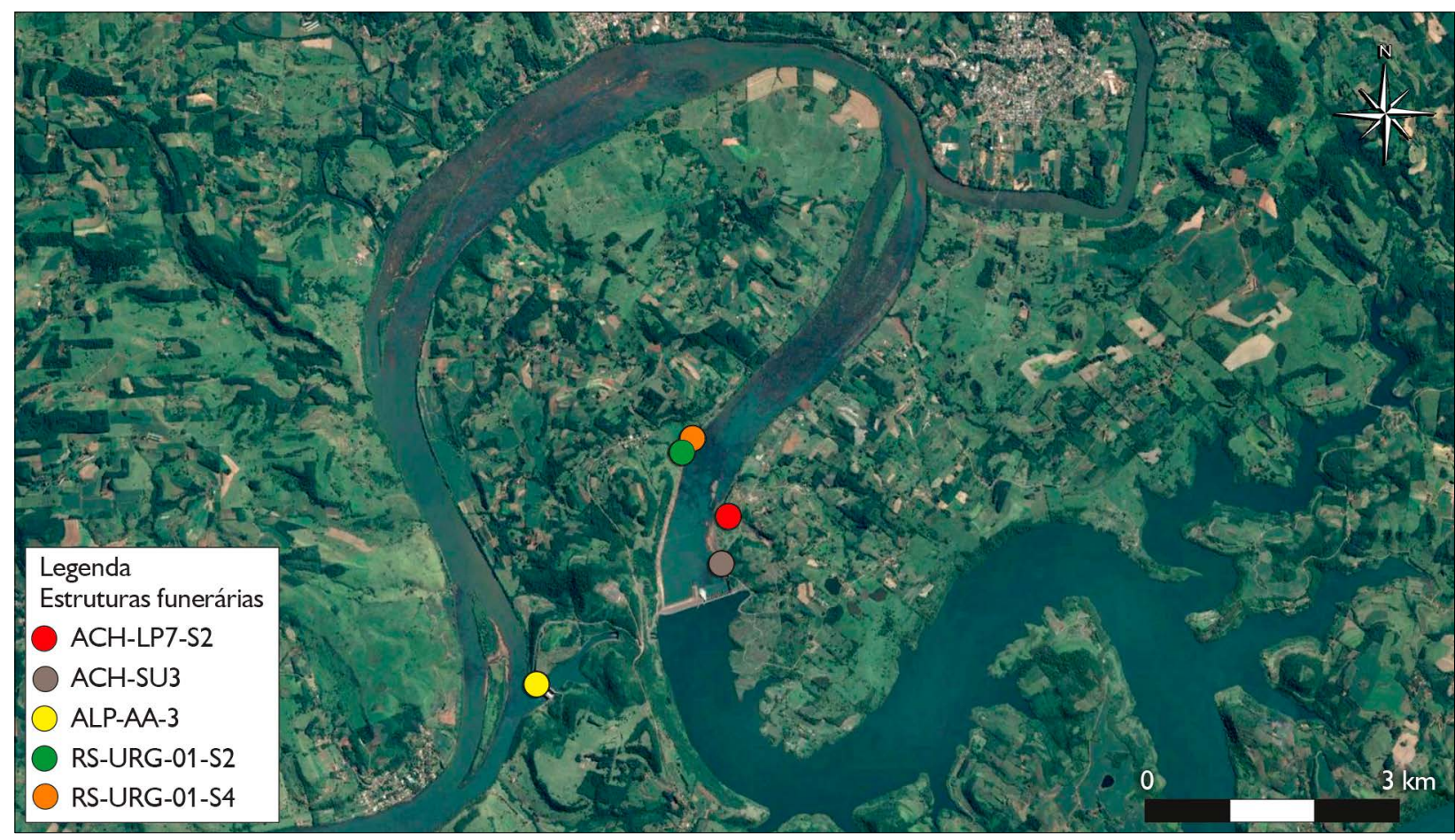

Figura 11. Sítios com estruturas funerárias no entorno próximo a ACH-LP-07. Sítios ALP-AA-3, com vasilhame cerâmico sem presença de ossos, e ACH-SU3-C2, com estruturas funerárias apresentadas por Müller e Souza (2011). RS-URG-01, setor 2 (enterramento direto) e setor 4 (deposição em urna) (Projeto POPARU, 2015 e 2017). Imagem feita por meio do software Google Earth. Mapa elaborado por Mirian Carbonera (2017).

Müller e Souza (2011) realizaram a escavação e a análise de sepultamentos encontrados em sítios registrados durante os estudos prévios à implantação do canteiro de obras da Usina Hidrelétrica Foz do Chapecó, especialmente no sítio ACH-SU3, sendo que duas datas o situam "[...] entre os anos de 1410 e 1460 AD [...]"(Müller; Souza, 2011, p. 213). Na concentração dois do sítio $\mathrm{ACH}-\mathrm{SU} 3$, foram descritas seis estruturas funerárias, o qual estava localizado a aproximadamente $800 \mathrm{~m}$ de distância de ACH-LP-07.

No sítio ALP-AA-3, localizado no município de Alpestre, Rio Grande do Sul, foi encontrada uma vasilha cerâmica. Devido à sua maior proporção e à sua posição em contexto, Müller e Souza (2011, p. 175) sugerem que poderia ter sido "[...] utilizada para sepultamento [...]", no entanto não foram encontrados ossos ou dentes. Ainda segundo as autoras, no sítio ACH-SU3-C2, localizado na margem catarinense do rio Uruguai, no município de Águas de Chapecó, Santa Catarina, foram encontradas seis estruturas, sendo que três delas estavam mais preservadas, possibilitando descrevê-las em maior detalhe. O sepultamento número três, segundo as autoras, apresentou no fundo do vasilhame cerâmico ossos e dentes de indivíduo adulto. A estrutura funerária de número quatro apresentou uma urna corrugada bem preservada, na parte interna, contas de gipsita e um vasilhame cerâmico corrugado pequeno como acompanhamentos funerários. Nesta, foram encontrados dentes de um indivíduo jovem, entretanto, os ossos estavam reduzidos a pó. Por fim, Müller e Souza (2011) informam, a respeito da estrutura funerária número cinco, que é composta por urna e tampa com acabamento corrugado, descrevendo dois vasilhames cerâmicos com acabamento liso como acompanhamento funerário. Estavam preservados ossos longos, crânio e dentes. As autoras concluem que seria

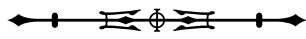


um sepultamento primário, principalmente em razão das conexões anatômicas, mas não descartam a possibilidade de ser secundário. Quanto ao vasilhame cerâmico utilizado como urna, constata-se que ele apresentava vestígios carbonizados na parte interna.

Conforme Caldarelli (2010), ainda em ACH-SU3-C2, foram encontradas outras três estruturas funerárias, sendo que a de número um foi quase completamente destruída pelas máquinas durante a construção da usina hidrelétrica e os poucos e pequenos vestígios ósseos encontrados estavam no fundo de uma vasilha. Os ossos aparentavam ser de adolescente ou de adulto; também na parte interna, como acompanhamento funerário, estava uma vasilha cerâmica de acabamento liso. O recipiente utilizado como urna apresentava acabamento externo corrugado e vestígios orgânicos carbonizados na face interna. Devido ao estado de destruição, não foi possível reconstituir a forma. Foram encontrados vestígios cerâmicos corrugados, que, por seu formato, poderiam ser do recipiente utilizado como tampa. Outros vestígios cerâmicos e líticos foram encontrados e poderiam estar associados ao contexto funerário. Segundo Caldarelli (2010), a estrutura dois havia sido desmontada pela ação das máquinas, restando muitos vestígios cerâmicos pertencentes a três recipientes distintos e alguns poucos ossos de indivíduo de adolescente ou de adulto, além de dentes. Por fim, a estrutura seis também havia sido quase totalmente revolvida pelas máquinas, sendo recuperados fragmentos cerâmicos e ossos. Entre os fragmentos de recipientes encontrados, estava associado um fragmento cerâmico que os autores interpretaram como não Guarani.

Cabe ressaltar, ainda, que as amostras ósseas, mesmo muito mal preservadas, podem ser submetidas a distintas análises, que trazem outros aspectos dessas culturas, como a dieta. Valores isotópicos de fragmentos ósseos dos sepultamentos escavados por Caldarelli (2010) apontaram um importante consumo de plantas $\mathrm{C}_{4}$ (como milho) (Loponte et al., 2016).

Ainda no entorno próximo, em frente ao sítio $\mathrm{ACH}$ LP-07, está o sítio RS-URG-01, no município de Alpestre,
Rio Grande do Sul, escavado desde 2015 dentro do projeto POPARU. Nele, também foram recuperadas duas deposições funerárias (Figura 11). Uma foi encontrada no setor 2: trata-se de uma deposição direta no sedimento, onde se escavou um crânio totalmente fragmentado e dentes. Distante uns 400 metros, no setor 4, recuperou-se uma deposição em urna, exposta pela ação da água de enchente, ocorrida em junho de 2017. Ambos estão ainda em análise e serão objeto de trabalho posterior.

\section{CONSIDERAÇÕES FINAIS}

A escavação da deposição funerária relacionada à unidade arqueológica Guarani, recuperada no setor 2 do sítio $\mathrm{ACH}$ LP-07, foi realizada de forma controlada e sistemática. A escavação em laboratório proporcionou o registro da posição espacial dos vestígios, mas também melhor interpretação do contexto funerário. A retirada em bloco do crânio, assim como o uso de tomografia 3D para este conjunto possibilitaram a preservação do material para pesquisas futuras.

Com base nos vestígios recuperados e analisados no setor 2 do sítio ACH-LP-07, relacionados às práticas funerárias encontradas, é possível sintetizar que: considerando a área de sepultamento no contexto do sítio, a interpretação inicial nesta pesquisa é a de que um grupo humano associado à unidade arqueológica Guarani teria ocupado a área como cemitério. A escavação no entorno, ainda em andamento - com a campanha de 2017 -, chegou a uma área de mais de $25 \mathrm{~m}^{2}$, sem encontrar evidências de um nível ceramista. Existe, sim, um nível arqueológico ao redor da urna (nível 1), mas exclusivamente lítico e tecnologicamente bem diferenciado do que se conhece na literatura sobre indústrias líticas associadas à unidade Guarani (Lourdeau et al., 2016). Trata-se, provavelmente, de nível resultante de ocupação pré-ceramista, que foi recortado no momento da escavação da fossa para enterrar a urna.

A data que associamos por enquanto à estrutura funerária, ao redor de 400 anos antes do presente, localiza o achado em contexto cronológico histórico. 
No entanto, o que se observa são práticas culturais da unidade Guarani do período anterior à conquista europeia. Quanto à deposição, tem-se a presença de urna e de tampa, mas ausência de acompanhamentos funerários. $\mathrm{O}$ sepultamento foi classificado como primário, conforme a manutenção de conexão anatômica entre os ossos longos dos membros inferiores, pelve, mandíbula e crânio (embora com queda sobre a região pélvica), a posição do eixo longitudinal e o direcionamento dos terços proximal e distal do úmero esquerdo e terço distal do úmero direito, assim como ossos metatarsais dos pés, mesmo considerando a completa decomposição da maioria do esqueleto, a exemplo da estrutura cinco descrita por Müller e Souza (2011). Pela presença dos terceiros molares erupcionados, trata-se de um indivíduo com idade superior a 21 anos (Brothwell, 1981; Ubelaker, 1984; White; Folkens, 2005). O sexo biológico não pôde ser estimado. $\bigcirc$ membro inferior esquerdo fêmures, tíbias e fíbulas - encontrava-se com manutenção da conexão anatômica e parcialmente verticalizado. O crânio encontrava-se depositado sobre a região da pelve, com a porção direita voltada para baixo e a mandíbula articulada. A degradação intensa dificultou a identificação dos ossos do lado direito do esqueleto.

Os dados bibliográficos regionais revelam a densidade de sítios arqueológicos com estruturas funerárias resultantes das ocupações relativas à unidade Guarani, que se estabeleceram nessa região do alto rio Uruguai principalmente a partir do último milênio. Na literatura, observam-se semelhanças nas descrições referentes às deposições funerárias, especialmente no tocante ao uso de recipientes cerâmicos para acomodar os mortos, evitando o contato com o solo. Em relação aos vasos utilizados, no geral, apresentam marcas de uso, com presença de manchas enegrecidas e na face interna; soma-se, ainda, fuligem de restos orgânicos queimados. Um elemento que distingue a deposição do sítio ACH-LP-07 da grande maioria é a ausência de acompanhamentos funerários. Os dados aqui apresentados trazem mais luz ao entendimento do comportamento mortuário desses grupos e as pesquisas em andamento no sítio RS-URG-01 irão possibilitar mais elementos, a fim de gerar novas comparações ao menos em escala regional.

\section{AGRADECIMENTOS}

Ao Hospital Unimed Chapecó, pela realização das imagens tomográficas, e a Lucas Camargo, pelo tratamento das imagens; ao Ministério das Relações Exteriores da França e ao edital Elisabete Anderle de Estímulo à Cultura, edição 2017, pelos recursos financeiros que possibilitaram essa pesquisa; ao Setor de Arqueologia da Universidade do Extremo Sul Catarinense; ao Instituto Goio-Ên e à Foz do Chapecó Energia S.A., pela parceria; a todos os profissionais e estudantes que contribuíram nas atividades de campo e no laboratório.

\section{REFERÊNCIAS}

AMBROSSETTI, Juan Bautista. Los cementerios prehistóricos del alto Paraná (Misiones). Boletín del Instituto Geografico Argentino, Buenos Aires, n. 16, p. 227-263, 1895.

BARKER, Philip. Techniques of archaeological excavation. 3rd ed. London: Routledge, 2002.

BASS, William M. Human osteology. A laboratory and field manual. 5th ed. Springfield: Missouri Archaeological Society, 2005. (Special Publication, n. 2).

BESCHÖREN, Maximiliano. Impressões de viagem na província do Rio Grande do Sul (1875-1887). Tradução de Ernestine Marie Bergmann e Wiro Rauber. Porto Alegre: Martins Livraria, 1989 [1889].

BONOMO, Mariano; ANGRIZANI, Rodrigo Costa; APOLINAIRE, Eduardo; NOELLI, Francisco Silva. A model for the Guarani expansion in the La Plata Basin and littoral zone of southern Brazil. Quaternary Internacional, Amsterdam, v. 356, p. 54-73, Jan. 2015. DOI: https://doi.org/10.1016/j.quaint.2014.10.050.

BROTHWELL, Don R. Digging up bones. 3rd ed. London: Cornell University Press, 1981.

BUIKSTRA, Jane E.; UBELAKER, Douglas H. (Ed.). Standards for data collection from human skeletal remains. Arkansas: Arkansas Archaeological Survey, 1994. (Arkansas Archeological Survey research series, n. 44).

CALDARELLI, Solange (Org.). Arqueologia preventiva na UHE Foz do Chapecó, SC/RS. Relatório final. Florianópolis: Scientia Consultoria Científica, 2010. 
CASTRO, Viviane Maria C. de; OLIVEIRA, Claudia Alves de; SILVA, Sérgio Francisco S. M. da; PEDROZA, Igor. Práticas funerárias dos grupos ceramistas pré-históricos do sítio Serra do Evaristo I, município de Baturité, Ceará. Mneme, Caicó, v. 16, n. 36, p. 201227, jan.-jul. 2015.

CÉSAR, José V. Enterros, em urnas, dos tupi-guaranis. In: SCHADEN, Egon (Org.). Homem, cultura e sociedade no Brasil. Petrópolis: Editora Vozes, 1977. p. 26-51.

CHMYZ, Igor. Dados arqueológicos do baixo rio Paranapanema e do alto rio Paraná. In: MUSEU PARAENSE EMÍLIO GOELDI. Programa Nacional de Pesquisas Arqueológicas: resultados preliminares do quinto ano, 1969-70. Belém: Museu Paraense Emílio Goeldi, 1974. p. 67-90. (Publicações Avulsas, 26).

CHMYZ, Igor; PIAZZA, Walter. A bacia do Uruguai e o seu povoamento pré-histórico. Dédalo, São Paulo, n. 6, p. 33-48, 1967.

DE MASI, Marco Aurélio Nadal. Relatório do Projeto de Salvamento Arqueológico UHE Foz do Chapecó (Reservatório). Florianópolis, 2012.

DIGANGI, Elizabeth A.; MOORE, Megan K. Research methods in human skeletal biology. London: Elsevier/Academic Press, 2013.

DUDAY, Henri. The archaeology of the death: lectures in Archaeothanatology. Oxford: Oxbow Books, 2009.

FERNÁNDEZ MARTÍNEZ, Víctor M. Teoria y metodo de la Arqueología. 2. ed. Madrid: Editorial Sintesis, 2000.

GOULART, Marilandi (Coord.). Levantamento de sítios arqueológicos na barragem de Itapiranga/SC. Florianópolis: UFSC/ ELETROSUL, 1985a.

GOULART, Marilandi (Coord.). Usina Hidrelétrica Itapiranga: estudo de viabilidade. Culturas indígenas do alto vale do rio Uruguai. Florianópolis: UFSC/ELETROSUL, 1985b.

GOULART, Marilandi (Coord.). Levantamento de sítios arqueológicos na barragem de Itapiranga/RS. Florianópolis: UFSC/ ELETROSUL, 1985c.

GOULART, Marilandi. Introdução. In: GOULART, Marilandi (Coord.). Projeto Salvamento Arqueológico do Uruguai. Itajaí: UNIVALI, 1997. v. 1.

KASHIMOTO, Emília M.; MARTINS, Gilson R. Arqueologia e paleoambiente do rio Paraná em Mato Grosso do Sul. Campo Grande: Life Editora, 2009.

KLAMPT, Sérgio. Uma contribuição para o sistema de assentamento de um grupo horticultor da Tradição Cerâmica Tupiguarani. Santa Cruz do Sul: EDUNISC, 2005.

KOELLN, Arno. Porto Feliz: a história de uma colonização às margens do rio Uruguai. 2. ed. Mondaí: Improeste, 2004.
LA SALVIA, Fernando; BROCHADO, José Proença. Cerâmica Guarani. 2. ed. Porto Alegre: Posenato e Cultura, 1989.

LAVINA, Rodrigo. Relatório final de levantamento arqueológico do canteiro de obras da UHE Foz do Chapecó, municípios de Águas de Chapecó/SC e Alpestre/RS. Criciúma: UNESC/ IPAT, 2004.

LAVINA, Rodrigo (Org.). Projeto de salvamento arqueológico da ZPE-Imbituba, SC. Relatório final. Criciúma: UNESC, 1999.

LOPONTE, Daniel; CARBONERA, Mirian; CORRIALE, María José; ACOSTA, Alexandro. Horticulturists and oxygen ecozones in the tropical and subtropical forests of Southeast South America. Environmental Archaeology, Aberdeen, v. 22, n. 3 , p. 247-267, July 2016. DOI: https://doi.org/10.1080/1461410 3.2016.1211382.

LOPONTE, Daniel Marcelo; ACOSTA, Alejandro; CAPPARELLI, Isabel; PÉREZ, Maricel. La arqueología guaraní en el extremo meridional de la cuenca del Plata. In: LOPONTE, Daniel Marcelo; ACOSTA, Alejandro (Ed.). Arqueología Tupiguaraní. Buenos Aires: Instituto Nacional de Antropología y Pensamiento Latinoamericano, 2011. p. 111-154.

LOTHROP, Samuel Kirkland. Indians of the Paraná Delta, Argentina. Annals of the New York Academy of Sciences, New York, v. 33, n. 1, p. 77-232, Dec. 1931. DOI: https://doi. org/10.1111/j.1749-6632.1931.tb55200.x.

LOURDEAU, Antoine; CARBONERA, Mirian; SANTOS, Marcos César Pereira; HOELTZ, Sirlei; FONTUGNE, Michel; HATTÉ, Christine; SILVA, Sérgio Francisco Serafim Monteiro da; ROSINA, Pierluigi; LUCAS, Lívia de Oliveira e; DA COSTA, Amelie; FOUCHER, Cécile; RAMALHO, Juliana Betarello; KUCZKOVSKI, Francieli; CAMPOS, Juliano Bitencourt; VIANA, Sibeli Aparecida; HERBERT, Ana Lucia. Pré-história na foz do rio Chapecó. Cadernos do CEOM, Chapecó, v. 29, n. 45, p. 220-242, dez. 2016. DOI: http://dx.doi.org/10.22562/2016.45.09.

MAACK, Reinhard. Geografia física do estado do Paraná. Curitiba: UFPR, 1968.

MAYS, Simon. The archaeology of human bones. 2nd ed. London: Routledge, 2010.

MAZZA, Bárbara; ACOSTA, Alexandro; LOPONTE, Daniel. Nuevos datos para las inhumaciones en urnas de sitios arqueológicos Guaraníes del extremo meridional de la Cuenca del Plata. Revista Chilena de Antropología, Nuñoa-Santiago, n. 34, p. 81-96, sem. 2016.

MILLER, Eurico T. Pesquisas arqueológicas efetuadas no Planalto Meridional, Rio Grande do Sul (rios Uruguai, Pelotas e das Antas). In: MUSEU PARAENSE EMÍLIO GOELDI. Programa Nacional de Pesquisas Arqueológicas: resultados preliminares do quarto ano, 1968-69. Belém: Museu Paraense Emílio Goeldi, 1971. p. 37-70. (Publicações Avulsas, 15).

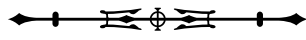


MILLER, Eurico T. Pesquisas arqueológicas efetuadas no Noroeste do Rio Grande do Sul (Alto Uruguai). In: MUSEU PARAENSE EMÍLIO GOELDI. Programa Nacional de Pesquisas Arqueológicas: resultados preliminares do segundo ano, 1966-67. Belém: Museu Paraense Emílio Goeldi, 1969. p. 33-54. (Publicações Avulsas, 10).

MÜLLER, Letícia M.; SOUZA, Sheila M. de. Enterramentos Guarani: problematização e novos achados. In: CARBONERA, Mirian; SCHMITZ, Pedro I. (Org.). Antes do oeste catarinense: arqueologia dos povos indígenas. Chapecó: Editora Argos, 2011. p. 167-218.

MÜLLER, Letícia M. Dentro do pote de barro: reflexões sobre os enterramentos Guarani através da sua cultura material. Cadernos do CEOM, Chapecó, v. 19, n. 24, p. 84-107, jul. 2006.

NOELLI, Francisco S. Sem Tekohá não há Tekó: em busca de um modelo etnoarqueológico da subsistência e da aldeia guarani aplicado a uma área de domínio no delta do Jacuí-RS. 1993. 488 f. Dissertação (Mestrado em História) - Pontifícia Universidade Católica do Rio Grande do Sul, Porto Alegre, 1993.

PALLESTRINI, Luciana. Sítio arqueológico Fonseca. São Paulo: Museu Paulista/Universidade de São Paulo, 1969.

PESTANA, Marlon. A Tradição Tupiguarani na porção central da planície costeira do Rio Grande do Sul, Brasil. 2007. 149 f. Dissertação (Mestrado em História) - Universidade do Vale do Rio dos Sinos, São Leopoldo, 2007.

PIAZZA, Walter. Dados complementares à arqueologia do vale do rio Uruguai. In: MUSEU PARAENSE EMÍLIO GOELDI. Programa Nacional de Pesquisas Arqueológicas: resultados preliminares do quarto ano, 1968-69. Belém: Museu Paraense Emílio Goeldi, 1971. p. 71-86. (Publicações Avulsas, 15).

PIAZZA, Walter. Notícia arqueológica do vale do Uruguai. In: MUSEU PARAENSE EMÍLIO GOELDI. Programa Nacional de Pesquisas Arqueológicas: resultados preliminares do segundo ano, 1966-67. Belém: Museu Paraense Emílio Goeldi, 1969. p. 55-70. (Publicações Avulsas, 10).

RIZZARDO, Fabiane. Sepultamentos dos mortos entre antigas populações do tronco Tupi: confrontando arqueólogos e cronistas quinhentistas. 2017. 120 f. Dissertação (Mestrado em História) Universidade do Vale do Rio dos Sinos, São Leopoldo, 2017.

RIZZARDO, Fabiane. Formas de sepultamento Tupiguarani. 2014. 57 f. Trabalho de Conclusão de Curso (Graduação em História) Universidade do Vale do Rio dos Sinos, São Leopoldo, 2014.
RIZZARDO, Fabiane; SCHMITZ, Pedro Ignácio. Formas de sepultamento na tradição cerâmica Tupiguarani. Revista Tecnologia e Ambiente, Criciúma, v. 21, n. 1, p. 140-161, anual 2015. DOI: http:// dx.doi.org/10.18616/ta.v21i0.1934.

ROHR, João Alfredo. Pesquisas arqueológicas em Santa Catarina, os sítios arqueológicos do município de Itapiranga. PesquisasAntropologia, São Leopoldo, n. 15, p. 21-60, 1966.

SCHMITZ, Pedro Ignácio. Um paradeiro Guarani no Alto Uruguai. Pesquisas-Antropologia, São Leopoldo, n. 1, p. 122-142, 1957.

SILVA, Osvaldo P.; MONTICELLI, Gislene; DOMIKS, Junior. Levantamento do patrimônio histórico, cultural e arqueológico na área diretamente afetada pela Usina Hidrelétrica Foz do Chapecó. Relatório de atividades. Florianópolis: Itaconsult Consultoria e Projetos em Arqueologia Ltda., 1998.

SILVA, Sérgio Francisco Serafim Monteiro da. Arqueologia funerária: corpo, cultura e sociedade. Ensaios sobre a interdisciplinaridade arqueológica no estudo de práticas mortuárias. Recife: Editora UFPE, 2014

SKIBO, James. Pottery function: a use-alteration perspective. Nova York: Plenum Press, 1992.

SOLARI, Ana; PEREIRA, Anderson Alves; ESPINOLA, Carolina Sá; MARTIN, Gabriela; COSTA, Ilca Pacheco da; SILVA, Sérgio Francisco Serafim Monteiro da. Escavações arqueológicas no abrigo funerário Pedra do Cachorro, Buíque. Clio Arqueológica, Recife, v. 31, n. 1, p. 105-135, sem. 2016.

SPRAGUE, Roderick. Burial terminology: a guide for researchers. New York: AltaMira Press, 2005

STEELE, Gentry D.; BRAMBLETT, Claud A. The anatomy and biology of the human skeleton. Texas: Texas A\&M University Press, 1988.

UBELAKER, Douglas $H$. Human skeletal remains: excavation, analysis, interpretation. Washington: Taraxacum Press, 1984.

VIGNATI, Milcíades Alejo. Censo óseo de paquetes funerarios de origen Guaraní. Revista del Museu de La Plata. Nueva Serie, La Plata, v. 2, n. 9, p. 1-11, sem. 1941

WHITE, Tim D.; FOLKENS, Pieter A. The human bone manual. London: Academic Press, 2005.

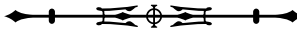

